\title{
Representações Sociais do Meio Ambiente e da Água
}

Social Representation of the Environment and Water

Representaciones Sociales del Medio Ambiente y del Agua

Gislei Mocelin Polli \&

Brigido Vizeu Camargo

Universidade Federal

de Santa Catarina

http://dx.doi.org/10.1590/1982-3703001622013

(cc) BY 
Resumo: Na atualidade, as questões relacionadas à temática ambiental têm despertado interesse da sociedade em geral e especialmente da comunidade científica. Considerando a importância que o meio ambiente assume em todas as esferas e o impacto que o seu cuidado ou degradação representa para todo o planeta, buscou identificar as representações sociais do meio ambiente e da água. Compuseram a amostra 150 pessoas da Cidade de Florianópolis, SC. Metade dos participantes de cada sexo, divididos em três faixas etárias, responderam questões de evocação livre com termos indutores "meio ambiente" e "água". As respostas foram tratadas pelos programas EVOC, Similitude e SPAD 7, e analisadas através da teoria do núcleo central. Os resultados indicam que a representação social do meio ambiente é formada pelos recursos que o compõem, preocupações com cuidado e seu papel como provedor de saúde. A representação social da água volta-se ao uso cotidiano, como provedora de saúde e vida e sua degradação. Foram identificadas relações entre as representações e diferenças de acordo com a faixa etária dos respondentes.

Palavras-chave: Representações Sociais. Meio Ambiente. Água. Evocações Livres.

Abstract: Today, issues related to environmental themes have aroused the interest of society and especially the members of the scientific community. Considering the importance of the environment and the impact that its care or degradation has on the planet, we sought to identify the social representations of the environment and water. The sample comprised 150 people of the city of Florianópolis, SC. half of each sex, divided into three age groups, who answered questions on free evocations, with the inductive terms of "environment" and "water." The responses were treated by programs such as EvOC, Similitude, and SPAD 7 and analyzed through the theory of the central nucleus. The results indicate that the social representation of the environment is formed by the resources that compose it, concerns regarding care, and its role as a health care provider. The social representation of water back up to its everyday use, as a provider of health and life; still comes to their degradation. We identified relations between representations as well as differences according to age of respondents.

Keywords: Social Representation. Environment. Water. Free Evocation.

Resumen: En la actualidad, las cuestiones relacionadas con los temas ambientales ha despertado el interés de la sociedad en general y en especial de la comunidad científica. Considerando la importancia que el medio ambiente tiene en todos los ámbitos y el impacto que su cuidado o degradación plantea para todo el planeta, se trató de identificar las representaciones sociales del medio ambiente y el agua. La muestra estuvo constituida por 150 personas de la ciudad de Florianópolis, SC. La mitad de los participantes de cada sexo, divididos en tres grupos de edad, respondieron a las preguntas de recuerdo libre con términos inductores "medio ambiente" y "agua". Las respuestas fueron tratados por los programas de EVOC, similitud y SPAD 7, y se analizaron por medio de la teoría del núcleo central. Los resultados indican que la representación social del medio ambiente está formada por los recursos que la componen, la preocupación por el cuidado y su papel como proveedor de atención médica. La representación social del agua es dirigida al uso cotidiano, como proveedor de la salud y la vida y su degradación. Se identificaron relaciones entre las representaciones y las diferencias según la edad de los encuestados.

Palabras clave: Representaciones Sociales. Ambiente. Agua. Evocaciones Libres. 
No cenário ambiental atual, figura um conflito entre a necessidade humana de obter conforto e o impacto ambiental, decorrência da modernização dos meios de produção que trouxe avanços a nossa sociedade. Tais avanços possibilitam acesso ilimitado aos bens de consumo, mas cobram um preço alto, a destruição da natureza. Essa facilidade na utilização dos recursos naturais promovida pelos avanços tecnológicos colocou a natureza à mercê do homem e, como consequência, os problemas ambientais se multiplicam e preocupam tanto ambientalistas e cientistas como a população em geral (Polli, Kuhnen, Azevedo, Fantin, \& Silva, 2009)

Pinheiro (2002) destaca que é importante ter em conta que os problemas ambientais são na realidade problemas na relação que as pessoas estabelecem com os recursos naturais, pois os seres humanos utilizam tais recursos como forma de prover suas necessidades. Esse uso pode acontecer de forma adequada ou inadequada, promovendo a degradação ou a sustentabilidade dos recursos naturais, de modo que os problemas ambientais têm sua origem na relação entre as pessoas e o ambiente, sendo o ser humano o principal responsável pela crise ambiental que se instala e se agrava.

A Psicologia Ambiental se insere nesse cenário, com o objetivo de compreender esta relação bidirecional entre pessoa e ambiente, entendendo que o ambiente exerce influência sobre a pessoa que, por sua vez, emite comportamentos, promovendo modificações no ambiente (Kuhnen, 2002; Wiesenfeld, 2005). Ao tratar dessa inter-relação, dois aspectos devem ser destacados: o primeiro é a forma como a pessoa pensa os aspectos do ambiente que a circunda, o segundo é o comportamento que ocorre a partir de tal representação e que, por sua vez, vai resultar em modificações no ambiente, que alteram as relações entre ele e a pessoa em um fluxo contínuo em que não se pode determinar o ponto de partida (Corral-Verdugo, 2005).

A teoria das representações sociais ocupa lugar de destaque no estudo sobre as relações que as pessoas estabelecem com o entorno. Por representação social entende-se uma forma de conhecimento compartilhado e elaborado socialmente e que possui um objetivo prático, contribuindo para a construção de uma realidade comum a um grupo social (Jodelet, 2001). A teoria das representações sociais teve origem na França, através do trabalho de Moscovici, em 1961, e surgiu com o interesse de compreender como o pensamento coletivo é organizado, assim como o próprio conteúdo do pensamento compartilhado socialmente.

Como bem marcado por Moscovici (1982) e Jodelet (2001), a razão pela qual as representações sociais são criadas está fortemente ligada à busca de um sentimento de conforto frente às situações novas ou estranhas. Mas, além da familiarização do não familiar, as representações sociais atendem a diferentes finalidades. Outra finalidade destacada por Moscovici (1978) éa orientação para comportamentos entre as pessoas na vida cotidiana, já que as representações sociais têm origem no processo de comunicação social. É importante considerar que as representações sociais estão intimamente ligadas às práticas sociais; visto que não são apenas as características objetivas de dada situação ou objeto que determinam o comportamento individual ou grupal, mas também a representação que as pessoas possuem acerca de tais objetos. As representações sociais podem também ser determinadas pelas práticas sociais, isto se refere às representações ideológicas, aquelas que são criadas para justificar a posteriori um comportamento. O interesse aqui é na situação em que a representação social funciona como um guia para a ação. Nesse caso, uma das suas funções essenciais é contribuir para a formação de processos que orientam a comunicação eo comportamento social (Rouquette, 1998). Por práticas sociais entendem-se as ações emitidas pelos indivíduos enquanto membros de um grupo (Wachelke \& Camargo, 2007).

O estudo das questões ambientais, através da teoria das representações sociais, permite que possamos compreender os conhecimentos que a população possui sobre a atual situação do planeta no que diz respeito aos recursos naturais. Possibilita também compreender como o conhecimento científico é apropriado pelas pessoas no discurso social e se torna conteúdo comum do saber popular (Félonneau, 2003). 
É importante considerar que as representações que as pessoas possuem sobre o meio ambiente estão ligadas às representações sobre os recursos naturais de modo geral, e também sobre a água em particular. Desse modo, identificar diferentes representações, e as relações que existem entre tais representações, fornece indicativo de como o modo de pensar sobre a temática ambiental se organiza, e como as representações sociais do meio ambiente e da água de relacionam, como uma forma de conhecer a arquitetura do pensamento popular sobre a temática.

A teoria do núcleo central possibilita o aprofundamento dos conhecimentos oriundos das representações sociais, de modo que os elementos que compõem uma dada representação podem ser identificados de acordo com a posição que ocupam nesse conhecimento. Seu estudo permite que se possa saber se um elemento é central ou periférico na representação, de modo a conhecer a estrutura da representação, o que possibilita uma melhor compreensão sobre o funcionamento da representação social e sua influência sobre os valores, atitudes, opiniões e comportamentos (Abric, 1998).

Atualmente a sociedade vem passando por uma transição de paradigmas ambientais. $\mathrm{O}$ paradigma social dominante (Human Exemptionalism Paradigm - HEP), também chamado de visão antropocêntrica, em que crenças de que a natureza é algo que pode ser controlado vem dando lugar a um novo paradigma. O novo paradigma ambiental (New Environmental Paradigm - NEP), também chamado de visão ecológica, envolve crenças de que o direitoà vida sob qualquer forma éfundamental, o equilíbrio da natureza é delicado, os recursos naturais são limitados e, portanto, necessitam de cuidado e equilíbrio (Nascimento-Schulze, Fragnani, Carboni, \& Maliska, 2002).

A mudança de paradigma ocorre lentamente, e cognições compatíveis com o primeiro tipo de crenças coexistem com cognições compatíveis com o segundo tipo mencionado. Por tais crenças serem compartilhadas socialmente através da comunicação social, é esperado que o momento de transição promova reflexos nas representações sociais do meio ambiente e dos elementos naturais que, em consequência da mudança de paradigma ambiental, podem estar passando por modificações. Diferenças entre as representações sociais de pessoas de faixas etárias distintas podem ocorrer, considerando-se que as pessoas mais jovens foram educadas com o predomínio do novo paradigma, enquanto as pessoas mais velhas foram expostas a ambos, participando do processo de transição.

Entre os problemas ambientais mais graves que a sociedade vem enfrentando estão os problemas relacionados à água. No ano 2000 foi criada a Agência Nacional das Águas (ANA) que tem como objetivos assegurar a sustentabilidade dos recursos hídricos para as gerações atuais e futuras, garantir a qualidade da água, e propor o uso racional do recurso visando o desenvolvimento sustentável (Moreira, 2006; Souza, 2004). Atualmente a escassez do recurso e sua falta de qualidade já se mostram visíveis em diversos pontos do planeta (Moraes \& Jordão, 2002). Além de ser um dos elementos naturais que tem despertado maior preocupação, a água está muito ligada às atividades diárias, e seu uso, desperdício ou cuidado, faz parte do cotidiano de todos os seres humanos. De modo que conhecer a ligação entre a representação social da água e sua relação com aspectos mais abrangentes do meio ambiente pode ser importante na busca da compreensão da dinâmica das representações sociais.

Tal conhecimento também pode ser utilizado como forma de identificação das informações que a população realmente possui sobre a água e o meio ambiente, fornecendo subsídios para penar programas voltados à educação ambiental. O pensamento popular sobre a água e o meio ambiente está intimamente ligado às práticas sociais, de modo que conhecer o que as pessoas pensam sobre o assunto nos fornecem indicativos sobre as ações que estabelecem com a água e o meio ambiente de forma geral, possibilitando um passo adiante no caminho em busca da preservação dos recursos naturais.

Este estudo buscou identificar os elementos que compõem as representações sociais da água e do meio ambiente, bem como as relações existentes entre tais representações em respondentes de três faixas etárias distintas. 


\section{Método}

\section{Participantes}

Responderam à pesquisa 150 pessoas que frequentam o Serviço Social do Comércio (SESC), unidade do bairro do Estreito, município de Florianópolis, SC. Dentre as pessoas que participaram do estudo, 75 (50\%) eram do sexo masculino e 75 (50\%) do sexo feminino. Houve divisão dos participantes também entre faixas etárias. A faixa etária 1 foi composta por respondentes com idade entre 18 e 29 anos ( $n=50)$; a faixa etária 2 foi composta por respondentes com idade entre 30 e 59 anos $(n=50)$; a faixa etária 3 foi composta por respondentes com 60 anos de idade ou mais $(n=50)$. A amostra foi controlada e em cada faixa etária houve metade de respondentes de cada sexo.

O controle da amostra em relação à faixa etária se deve ao fato de que as diferentes faixas etárias foram expostas de forma distinta aos diferentes paradigmas ambientais, sendo que os respondentes da faixa etária 3 (60 anos ou mais) tiveram sua educação formal realizada no período que em que o paradigma dominante era o antropocêntrico; os respondentes da faixa etária 2 (de 30 até 59 anos) tiveram sua educação formal realizada num período de transição entre os paradigmas e os respondentes da faixa etária 1 (18 até 29 anos) foram educados sob a prevalência do paradigma ecológico.

\section{Instrumentos}

Os instrumentos foram apresentados em duas versões distintas em que a ordem dos elementos apresentados foi alternada, metade dos questionários iniciava por questões sobre a água e a outra metade por questões sobre o meio ambiente, de modo a evitar algum enviezamento nas respostas devido à ordem de apresentação das questões.

O instrumento foi composto de diferentes tipos de questões, iniciando por questões de evocação livre. Os respondentes deveriam enumerar 5 palavras que lhes viesse à cabeça ao ler as palavras indutoras - Água e Meio Ambiente. Em seguida, pediu-se que os participantes indicassem as 2 palavras que consideravam mais importantes entre as quais haviam apontado.

A segunda parte do instrumento, voltada à identificação de informações que os respondentes possuíam sobre a água e o meio ambiente, não será tratada nesse trabalho. Na última parte do instrumento foram apresentadas questões para levantamento do perfil sócio econômico.

\section{Procedimentos}

Após aprovação do projeto de pesquisa pelo comitê de ética em pesquisa com seres humanos da UFSC foi realizado contato com a assistente social do SESC Estreito. Depois de obtida a aprovação por parte da diretoria do SESC-SC, deu-se início à coleta de dados. Os respondentes foram convidados a participar e esclarecidos sobre o sigilo e o anonimato em relação aos dados individuais. Assinaram o termo de consentimento livre e esclarecido (TCLE) e responderam ao questionário individualmente. Alguns respondentes com faixa etária mais elevada, e algumas vezes com dificuldades para a leitura, responderam ao instrumento em forma de entrevista. A pesquisadora fez oralmente as perguntas e tomou nota das respostas.

\section{Análise de Dados}

A análise dos dados de associação livre foi realizada com o auxílio do programa Evocation 2000 (EVOC) (Vèrges, 1999) que fornece a frequência simples das palavras evocadas e a ordem de evocação média de cada palavra. Obtém-se uma distribuição das palavras em quatro quadrantes através do qual se torna possível identificar os elementos centrais e periféricos da representação social. Na sequência, foi realizada uma análise confirmatória para verificar as palavras de que se confirmaram como compondo o núcleo central.

Em seguida os dados foram tratados utilizando o programa Similitude 2000 (SIMI) (Vèrges, 1997) que permite visualizar as conexões existentes entre os elementos da representação social. As palavras semanticamente próximas foram agrupadas em categorias e analisadas através do programa 
SIMI, que possibilitou a criação de gráficos que ajudam na visualização da organização da representação social.

Com o objetivo de identificar possíveis diferenças entre os grupos, no que se refere ao sexo e à faixa etária dos respondentes, foi realizada uma análise fatorial de correspondência com o auxílio do programa Systhème Portable pour l'Analyse des Données Textuelles (SPAD 7) que possibilita retenção e apresentação gráfica de conjuntos de variáveis qualitativas em relação a um objeto, de modo a evidenciar as inter-relações que existem entre cada conjunto de variáveis.

\section{Resultados}

Representações sociais do meio ambiente

Em resposta a solicitação: Escreva 5 palavras ou expressões que the vêm imediatamente à cabeça ao se falar MEIO AMBIENTE, foram feitas 718 evocações com 163 palavras diferentes. A frequência mínima para que uma palavra deveria ter sido evocada para fazer parte do corpus de análise foi 6 , de modo que foram consideradas $71,4 \%$ das palavras evocadas. Considerando a proximidade semântica, foram criadas 21 categorias das quais fizeram parte $100 \%$ das palavras evocadas. A frequência média de palavras por categoria foi de 7,76 (Torres, 2010).

Os resultados obtidos estão expressos através da distribuição nos quadrantes (ver Quadro 1). Acima da linha horizontal estão as palavras que foram evocadas 16 vezes ou mais, abaixo as palavras evocadas entre 6 e 16 vezes. A esquerda do eixo vertical estão as palavras evocadas em primeira ou segunda posição, e a sua direita as palavras evocadas após a terceira posição.

Pode-se verificar que a representação social do meio ambiente para o grupo estudado é possivelmente formada pelos seguintes

Quadro 1. Diagrama de quadrante das palavras evocadas a partir do termo indutor meio ambiente.

\begin{tabular}{cccccc}
\hline & OME $\leq \mathbf{2}$ & \multicolumn{4}{c}{ OME > 3 } \\
\hline Palavras & Freq & OME & Palavras & Freq & OME \\
\hline animais & 40 & 2,875 & desmatamento & 25 & 3,080 \\
florestas & 28 & 2,429 & lixo & 19 & 3,053 \\
natureza & 23 & 1,913 & plantas & 21 & 3,238 \\
preservação & 46 & 2,109 & poluição & 45 & 3,044 \\
saúde & 21 & 2,667 & rios & 16 & 3,125 \\
água & 42 & 2,595 & vida & 30 & 2,900 \\
árvores & 19 & 2,158 & & & \\
Freq $\geq 16$ & & & & & \\
\hline Freq $<16$ & & & & \\
bem-estar & 6 & 2,667 & ar puro & 7 & 3,571 \\
consciência & 12 & 2,667 & coletividade & 6 & 3,667 \\
educação & 9 & 2,889 & descaso & 7 & 3,286 \\
limpeza & 6 & 2,500 & destruição & 9 & 3,000 \\
qualidade de vida & 8 & 2,875 & mar & 8 & 3,375 \\
reciclagem & 9 & 2,444 & md-climáticas & 8 & 3,625 \\
saneamento & 6 & 2,667 & planeta & 8 & 3,250 \\
verde & 6 & 2,167 & reflorestamento & 6 & 4,000 \\
& & \multicolumn{5}{c}{ sustentabilidade } & 6 & 3,500 \\
\hline
\end{tabular}

Nota. Freq = Frequência; OME = ordem média de evocação. 
elementos organizadores: animais, florestas, natureza, preservação, saúde, água e árvores.

A análise confirmatória das palavras pertencentes ao núcleo central, feita a partir das palavras que os respondentes consideraram como mais importantes, confirmou a centralidade de três das sete palavras do primeiro quadrante $\left({ }^{*}\right.$ preservação, *saúde e *água). O elemento *poluição, pertencente ao segundo quadrante, também foi confirmado como central. A presença de tais palavras como pertencentes ao núcleo central da representação evidencia que a representação social do meio ambiente está ligada à preocupação com o cuidado que se deve ter com ele, expresso através dos elementos preservação e poluição. O elemento saúde evidencia que a interferência que o meio ambiente exerce sobre a saúde é fortemente reconhecida pela população respondente. O elemento água aparece como um dos componentes do meio ambiente e o que possui maior ligação ou importância para os participantes.

Ao se identificar que o elemento água possui lugar no núcleo central da representação social do meio ambiente foi realizada uma investigação. Verificou-se que o elemento água teve 42 evocações no total, das quais 30 foram feitas pelos participantes que responderam a versão do instrumento que iniciava por questões relativas ao meio ambiente. De modo que se pode concluir que o elemento água é de fato central na representação social do meio ambiente, não sendo a sua presença devido a algum viés de pesquisa.

Outros elementos que formam o meio ambiente são partes que compõem a periferia da representação como animais, florestas, árvores, plantas e rios. A preocupação com seu cuidado também se manifesta através dos elementos desmatamento e lixo. O elemento natureza aparece como sinônimo e o elemento vida evidencia a importância atribuída ao meio ambiente como possibilitador da vida.

Ao considerar as repostas evocadas de acordo com o sexo dos respondentes, verificou-se que os elementos de destaque estão presentes na representação social do meio ambiente de ambos os grupos. Para as mulheres, elementos descritivos do meio ambiente são apontados com mais destaque, como é o caso dos elementos rios e árvores, que não estão presentes com muita frequência nas respostas dos homens. O elemento lixo também é destacado com mais importância para as mulheres, fator que pode estar relacionado ao hábito cotidiano de separar o lixo orgânico do lixo reciclável.

Ao analisar as respostas diferenciando entre as três faixas etárias estudadas, pode-se identificar que o elemento saúde, central na representação social do meio ambiente, não recebeu destaque entre os respondentes da faixa etária 1 (18 até 29 anos). Os elementos água e preservação se mostraram importante para os três grupos. Outros elementos importantes na representação social do meio ambiente também se apresentaram distribuídos de maneira desuniforme entre os respondentes das três faixas etárias, indicando que, apesar de possuir um núcleo central semelhante, os elementos periféricos variam entre os grupos. Exemplo é o elemento animais que, embora esteja presente em todos os grupos, recebe destaque entre os respondes da faixa etária 1 (entre 18 e 29 anos). Já o elemento florestas tem destaque entre os respondentes das faixas 2 (entre 30 e 59 anos) e 3 (60 anos ou mais), e não recebe ênfase dos respondentes da faixa 1 . O elemento árvores, bastante evidenciado pelos respondentes das faixas 1 e 2 foi muito pouco lembrado pelos respondentes da faixa etária 3 .

Ainda que não tenham sido encontradas diferenças entre os respondentes do sexo feminino e do sexo masculino em relação aos elementos que compõem a representação social do meio ambiente, podem-se notar algumas diferenças ao separar os respondentes de acordo com a faixa etária em que se enquadram.

A análise fatorial de correspondência (AFC) realizada a partir das palavras evocadas em resposta à questão sobre o meio ambiente permitiu identificar contrastes entre os grupos, diferidos por sexo (masculino e feminino) e faixa etária (faixa 1 - 18 até 29 anos, faixa 
2 - 30 até 59 anos, e faixa $3-60$ anos ou mais), estas foram as variáveis consideradas na análise efetuada com o auxílio do programa SPAD 7.

Ao relacionar as palavras com as variáveis sexo e faixa etária, obtiveram-se três fatores que explicam $100 \%$ da variância encontrada. O primeiro fator explica $55,29 \%$, o segundo fator explica $27,04 \%$ e o terceiro fator explica $17,67 \%$. Foram consideradas variáveis que contribuíram para cada fator aquelas que contribuíram com aproximadamente $20 \%$ da variância de cada fator. Esse índice foi obtido através da divisão de 100 pelo número de variáveis (5). Para delimitação do ponto de corte das palavras, foi dividido 100 pelo número de palavras (36), sendo consideradas integrantes do fator as palavras que apresentaram uma contribuição duas vezes maior que o ponto de corte $(2,77)$.

O primeiro fator foi o mais representativo na análise fatorial, pois representa 55,29\% da variância. Observa-se que os respondentes da faixa etária 1 (18 até 29 anos) se contrapõem aos respondentes da faixa etária 3 (60 anos ou mais). Nesse fator, de um lado, ligado à faixa 1, estão os elementos voltados aos recursos que compõem o meio ambiente, como animais, natureza e verde: esses elementos indicam descrições do meio ambiente, utilizando-se de sinônimos ou ainda da descrição dos elementos que o compõem ou mesmo se utilizam dele. Do outro lado, ligado à faixa 3 os elementos rios e limpeza indicam elementos que compõem o meio ambiente e também uma preocupação com o seu cuidado.

O segundo fator explica $27,04 \%$ da variância e contrapõe os respondentes do sexo feminino e do sexo masculino. Ligados aos respondentes do sexo masculino estão os elementos descaso e sustentabilidade que indicam preocupações com o meio ambiente, assinalando como vem sendo tratado e apontando uma solução. Ligados aos respondentes do sexo feminino estão os elementos terra, higiene e reciclagem. Tais elementos também indicam preocupações com o cuidado com o meio ambiente, além de apontar um possível sinônimo e indicar uma necessidade.

O terceiro fator, responsável por $17,67 \%$ da variância, contrapõe os elementos mais característicos dos respondentes a faixa etária 2 (30 até 59 anos) e faixa etária 3 (60 anos ou mais). Ligados aos respondentes da faixa etária 2 estão os elementos vida, saúde, responsabilidade e água. Tais elementos se referem à forma como o meio ambiente deve ser tratado; um de seus elementos também é destacado, além de enfatizarem o valor do meio ambiente para a saúde e a vida. Os elementos que estão ligados às respondentes da faixa etária 3 são rios, limpeza e verde. Para estes respondentes recebem destaque os componentes do meio ambiente e também a preocupação com seu cuidado.

A Figura 1 é a apresentação gráfica o plano cartesiano dos dois primeiro fatores, que somam $82,33 \%$ da variância na AFC. Os elementos que contribuíram para o fator 1 estão sublinhados, os que contribuíram para o fator 2 estão em itálico, os elementos que contribuíram para os dois fatores estão sublinhados e em itálico.

A Figura 1 demonstra o plano fatorial dividido através do eixo das abscissas em superior e inferior e através do eixo das ordenadas em direito e esquerdo. É possível observar que do lado direito encontram-se os elementos que foram mencionados pelos respondentes da faixa etária 1 . Ao lado esquerdo do eixo das ordenadas estão os elementos característicos dos respondentes da faixa etária 3. Esses elementos compõem o fator $1 . \mathrm{Na}$ parte superior da figura estão os elementos característicos dos respondentes do sexo feminino, na parte inferior da figura estão os elementos ligados aos respondentes do sexo masculino, separados pelo eixo das abscissas. Esses elementos compõem o fator 2.

Com o intuito de identificar a forma como os elementos da representação sociais do meio ambiente estão organizados, realizou-se uma análise de similitude com o auxílio do programa SIMI. Os elementos evocados são agrupados em categorias por sua proximidade 


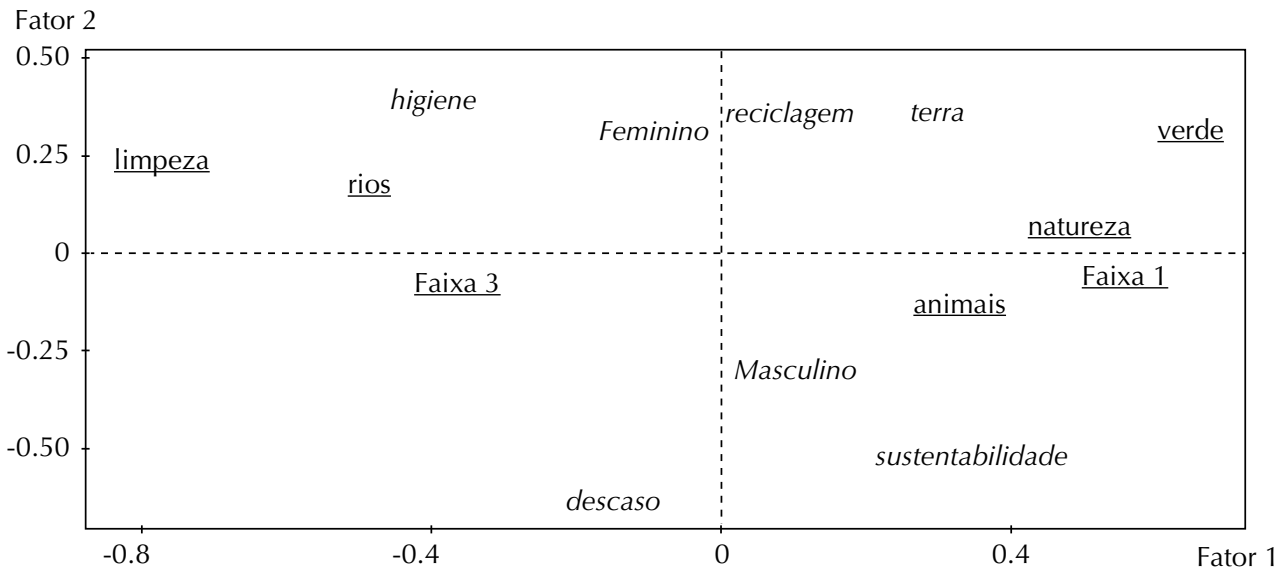

Figura 1. Representação gráfica (fator 1 x fator 2) em relação à AFC (palavras x elementos).

semântica (a distribuição dos elementos por categorias se encontra no apêndice). A árvore máxima permite que a conexidade entre os elementos possa ser conhecida. Para uma primeira visualização, utilizou-se o clique 12, ou seja, compõem a árvore máxima (Figura 2) as categorias que são compostas por elementos que foram evocados simultaneamente 12 vezes ou mais.

A Figura 2 demonstra que a representação social do meio ambiente possui uma organização um tanto difusa. Os elementos apresentam conexões entre si, mas nenhuma categoria se destaca como organizadora da representação. É possível notar que categorias como ações positivas e soluções estão ligadas. Assim como poluentes e problemas. Esse tipo de organização parece indicar que a representação social do meio ambiente possui um caráter linear, em que nenhuma das categorias se destaca como organizadora da representação como um todo.

Essa organização pode indicar o caráter multifacetado da representação, já que para alguns respondentes meio ambiente é um lugar onde se vive, para outro é um lugar onde tem plantas e animais, para outros é um lugar que tem problemas e poluição. Há ainda um grupo que acredita que ações positivas são necessárias para que se possam ter soluções. É importante destacar que uma forma de pensar o meio ambiente não exclui

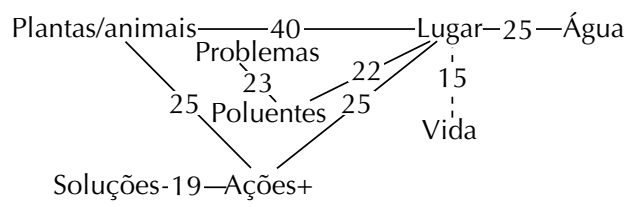

Figura 2. Árvore máxima de 15 co-ocorrências referente ao termo de evocação meio ambiente.

as demais, podendo um mesmo respondente considerar todas as opções citadas.

Representações sociais da água

Em resposta a solicitação: Escreva 5 palavras ou expressões que lhe vêm imediatamente à cabeça ao se falar em ÁGUA, foram feitas 737 evocações com 138 palavras diferentes. A frequência mínima para que uma palavra deveria ter sido evocada para fazer parte do corpus de análise foi 6 , de modo que foram consideradas $71,8 \%$ das palavras evocadas.

Considerando a proximidade semântica foram criadas 25 categorias das quais fizeram parte $100 \%$ das palavras evocadas. A frequência média de palavras por categoria foi de 5,52, as quais foram lembradas em média na terceira posição (ordem média de evocação $=2,97$ ).

Os resultados obtidos estão expressos através da distribuição nos quadrantes (ver Quadro 2). Acima da linha horizontal estão as palavras 
que foram evocadas 16 vezes ou mais, abaixo as palavras evocadas entre 6 e 16 vezes. A esquerda do eixo vertical estão as palavras evocadas em primeira ou segunda posição, e a sua direita as palavras evocadas após a terceira posição.

Pode-se verificar que a representação social da água para o grupo estudado é possivelmente formada pelos seguintes elementos organizadores: banho, beber, higiene, potável, saúde, sede e vida. A análise confirmatória das palavras pertencentes ao núcleo central, feita a partir das palavras que os respondentes consideraram como mais importantes, confirmou a centralidade de 5 das 7 palavras do primeiro quadrante (*banho, *beber, *saúde e *vida). Além dessas palavras, foi confirmada a centralidade de uma palavra pertencente ao segundo quadrante (*poluição). A presença de tais palavras como pertencentes ao núcleo central da representação evidencia que a representação social da água está ligada ao seu uso no cotidiano, banho e beber, à sua função de promotora de vida e também de saúde. A presença do elemento poluição parece evidenciar uma preocupação que se mostra presente quando se pensa em água.

Os elementos periféricos como higiene, potabilidade, sede e limpeza reforçam a importância que o uso cotidiano da água recebe. A preocupação com a água também está presente no sistema periférico através dos elementos escassez e importante. Suas possíveis formas também compõem o sistema periférico, através das palavras chuva, mar e rios.

Ao analisar a evocação de palavras de acordo com o sexo dos respondentes, verificou-se que as palavras confirmadas como elementos centrais da representação social da água foram evocadas pelos respondentes de ambos os sexos. As respondentes do sexo feminino

Quadro 2. Diagrama de quadrante das palavras evocadas a partir do termo indutor água.

\begin{tabular}{cccccc}
\hline & OME $\leq \mathbf{2}$ & \multicolumn{5}{c}{ OME $>\mathbf{3}$} \\
\hline Palavras & Freq & OME & Palavras & Freq & OME \\
\hline banho & 17 & 2,235 & chuva & 16 & 3,625 \\
beber & 21 & 2,476 & escassez & 18 & 3,056 \\
higiene & 19 & 2,737 & importante & 22 & 3,045 \\
potável & 19 & 2,211 & limpeza & 35 & 3,171 \\
saúde & 44 & 2,682 & mar & 22 & 3,227 \\
sede & 32 & 2,438 & poluição & 22 & 2,909 \\
vida & 57 & 2,579 & rios & 19 & 3,000 \\
Freq $\geq 16$ & & & & \\
\hline Freq $<16$ & & & & \\
cristalina & 6 & 2,333 & alimento & 15 & 3,267 \\
economia & 7 & 2,429 & desperdício & 14 & 3,286 \\
limpa & 12 & 2,583 & energia & 6 & 3,167 \\
meio ambiente & 6 & 2,833 & lazer & 8 & 4,250 \\
necessidade & 13 & 2,615 & natureza & 10 & 3,100 \\
pura & 7 & 1,714 & plantas & 11 & 3,364 \\
pureza & 13 & 2,846 & preservação & 10 & 3,500 \\
tratada & 7 & 2,286 & refrescante & 7 & 4,000 \\
& & saneamento & 8 & 3,500 \\
& & suja & 6 & 3,833 \\
\hline
\end{tabular}

Nota. Freq = Frequência; OME = ordem média de evocação. 
apontaram, além dos elementos comuns a ambos os grupos, outros elementos que se diferenciam dos elementos centrais. Para as mulheres, elementos como escassez, importante e pureza tiveram destaque e indicam uma preocupação mais acentuada com a disponibilidade e qualidade da água em comparação com os homens.

Considerando a faixa etária dos respondentes, pode-se verificar que elementos centrais como vida e saúde constam como elementos importantes para todas as faixas. Já o elemento central banho está presente de maneira significativa nas respostas das pessoas da faixa etária 3 (60 anos ou mais), não tendo destaque nas demais faixas etárias. Os elementos beber e sede, embora tenham sido considerados elementos distintos remetem a um significado semelhante, considerando os dois elementos em conjunto, pode-se dizer que se distribuem de maneira uniforme entre os três grupos.

Elementos que remetam à qualidade da água para o consumo, como o elemento central potável, não possuem destaque entre os respondentes da faixa etária 2 (entre 30 e 59 anos), mas se mostra como elemento importante para as demais faixas etárias. Já o elemento poluição, central para o grupo como um todo, não recebe destaque para os respondentes da terceira faixa etária (60 anos ou mais), e tem sua maior importância destacada pelos respondentes da faixa etária 2 (de 30 até 59 anos); mas recebe destaque também pelos respondentes da faixa etária 1 (entre 19 e 29 anos).

A análise fatorial de correspondência (AFC) realizada a partir das palavras evocadas em resposta à questão sobre a água permitiu identificar contrastes entre os grupos, diferidos por sexo (masculino e feminino) e faixa etária (faixa $1-18$ até 29 anos, faixa $2-30$ até 59 anos, e faixa 3 - acima de 60 anos), estas foram as variáveis consideradas na análise efetuada com o auxílio do programa SPAD 7.

Ao relacionar as palavras com as variáveis sexo e faixa etária, obtiveram-se três fatores que explicam $100 \%$ da variância encontrada.
O primeiro fator explica 50,09\%, o segundo fator explica $29,17 \%$ e o terceiro fator explica $20,74 \%$. Foram consideradas variáveis que contribuíram para cada fator aquelas que contribuíram com aproximadamente $20 \%$ da variância de cada fator. Esse índice foi obtido através da divisão de 100 pelo número de variáveis (5). Para delimitação do ponto de corte das palavras, foi dividido 100 pelo número de palavras (32), sendo consideradas integrantes do fator as palavras que apresentaram uma contribuição duas vezes maior que o ponto de corte $(3,13)$.

O primeiro fator foi o mais representativo na análise fatorial, pois representa 50,09\% da variância. Observa-se que os respondentes da faixa etária 1 (18 até 29 anos) se contrapõem aos respondentes da faixa etária 3 ( 60 anos ou mais). Nesse fator, de um lado, ligado à faixa 1, estão os elementos voltados a aspectos mais conceituais da água, como energia, natureza e escassez; esses elementos indicam preocupações com o uso da água para a utilização por todos, no caso da produção de energia, preocupação também mais ampla com sua escassez, que prejudica a todos. São elementos que tratam das formas de manifestação da água e também de preocupações. Do outro lado, ligado à faixa 3 se contrapõem os elementos concretos, ligados ao uso cotidiano da água, elementos banho e limpeza; tais elementos indicam uma preocupação mais imediata e individual com os benefícios que a água proporciona no dia a dia.

O segundo fator explica 29,17\% da variância e contrapõe os respondentes da faixa 2 (30 até 59 anos) e faixa 3 (60 anos ou mais). Ligada à faixa etária 2 está o elemento pura que é bastante representativo desse grupo (contribuição de 20,6) e indica preocupação com a qualidade da água, indicando uma possível, e desejada, característica. Ligados aos respondentes da faixa etária 3 estão os elementos limpa, rios e tratada. Tais elementos também indicam preocupações com a qualidade da água, com suas formas de manifestação, ou podem, ainda, enumerar suas características positivas. 
O terceiro fator, responsável por 20,74\% da variância, contrapõe os elementos mais característicos dos respondentes do sexo masculino e do sexo feminino. Ligados aos respondentes do sexo masculino estão os elementos refrescante, potável e vida. Tais elementos se referem às características da água, destacando-se seu valor para a vida, algo possibilitado pela água. Os elementos que estão ligados às respondentes do sexo femininos são economia, pureza, lazer e mar. Para estas respondentes, além das características e manifestações da água, também recebe importância a necessidade de economia da água para sua manutenção, indicando preocupação.

A Figura 3 é a apresentação gráfica o plano cartesiano dos fatores 1 e 3, que representam $70,83 \%$ da variância na AFC. Os elementos que contribuíram para o fator 1 estão sublinhados, os que contribuíram para o fator 3 estão em itálico.

A Figura 3 demonstra o plano fatorial dividido através do eixo das abscissas em superior e inferior e através do eixo das ordenadas em direito e esquerdo. É possível observar que do lado direito encontram-se os elementos que foram mencionados pelos respondentes da faixa etária 3. Ao lado esquerdo do eixo das ordenadas estão os elementos característicos dos respondentes da faixa etária 1 . Esses elementos compõem o fator 1. Na parte superior da figura estão os elementos característicos dos respondentes do sexo masculino, na parte inferior da figura estão os elementos ligados aos respondentes do sexo feminino. Esses elementos compõem o fator 3.

Com o objetivo de identificar a conexidade existente entre os elementos que compõem a representação social da água entre os respondentes foi gerada a árvore máxima da representação com o auxílio do programa SIMI. O filtro utilizado foi de 12 co-ocorrências. O que significa dizer que no gráfico serão apresentados os elementos que foram lembrados conjuntamente por pelo menos 12 respondentes. É importante lembrar que a análise de co-ocorrências não é realizada a partir das palavras evocadas, mas de categorias criadas a posteriori. A Figura 2 apresenta a árvore máxima da representação

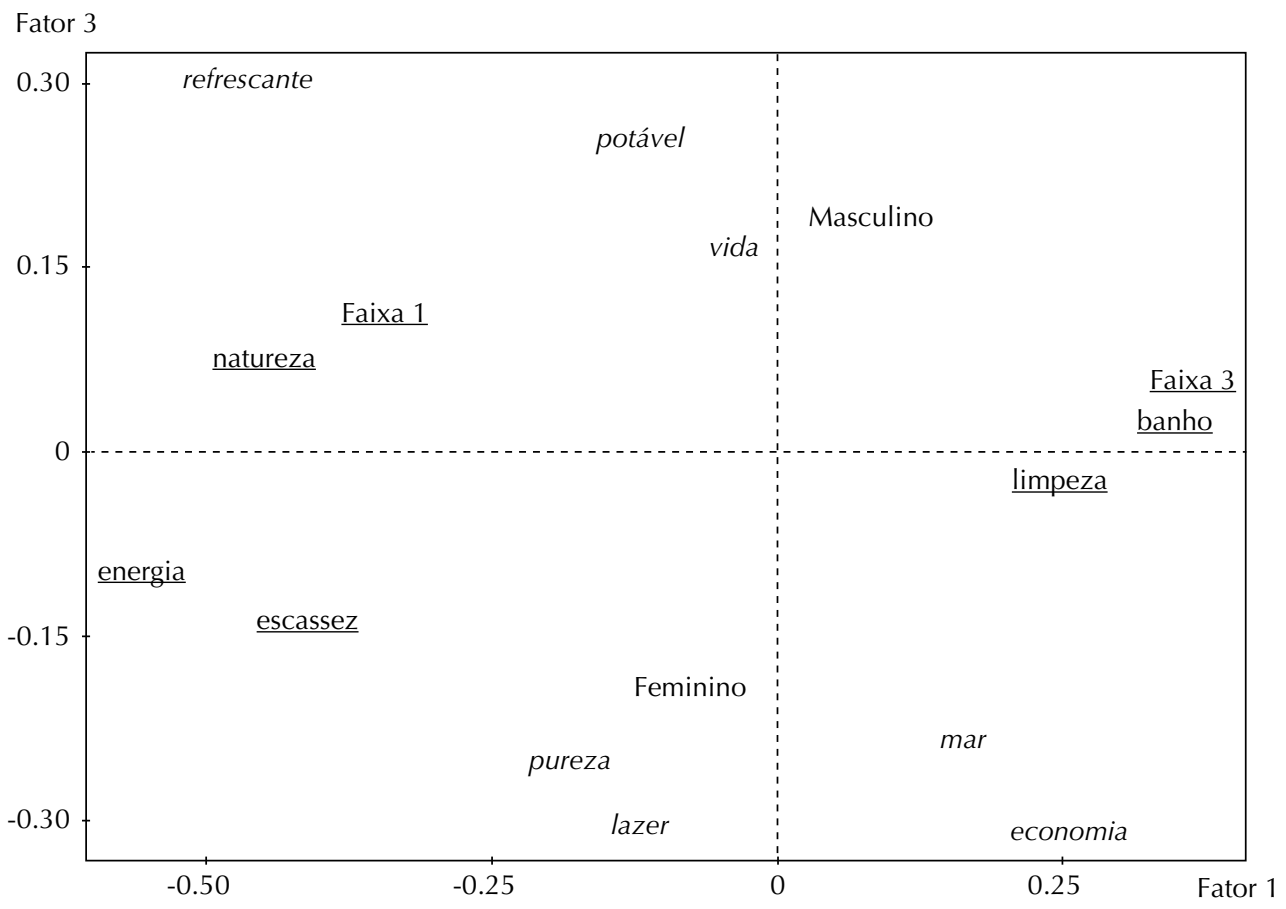

Figura 3. Representação gráfica (fator 1 x fator 3) em relação à AFC (palavras x elementos). 
social da água considerando, no mínimo, 12 co-ocorrências.

Pode-se notar o papel organizador que a categoria cotidiano possui na representação social da água. Essa categoria organiza outras ao redor de si, de modo que, ao observar a Figura 2, é possível identificar que as categorias vida e cotidiano organizam a representação social da água para o grupo estudado. As representações sociais possuem elementos que se ligam a uma das duas categorias, direta ou indiretamente.

Significa dizer que o pensamento social sobre a água se relaciona com seu uso, suas possibilidades, suas manifestações, suas preocupações ligadas ao cotidiano dos respondentes. Ou ainda, quando a água é considerada de uma forma mais ampla, deixa-se o dia a dia um pouco de lado, e o pensamento volta-se para a preocupação com a saúde e a manutenção da vida.

\section{Relação entre RS da água e do meio} ambiente

Por meio da comparação entre os elementos que compõem o sistema central de duas representações sociais, é possível identificar a relação que existe entre tais representações. Conforme Flament e Rouquette (2003) as relações entre as representações sociais podem ser de quatro tipos distintos. O primeiro, denominado disjunção, é quando não existe coincidência entre nenhum dos elementos centrais das duas representações. Conjunção refere-se à existência de pelo menos um

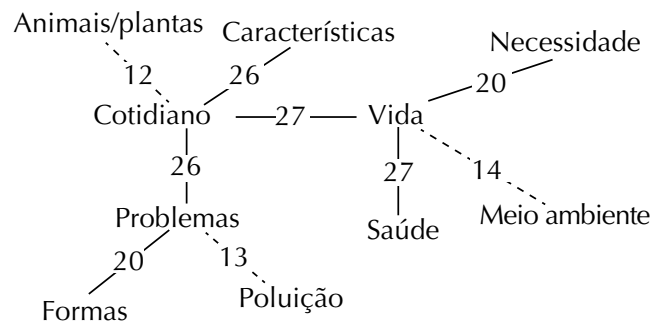

Figura 4. Árvore máxima de 12 co-ocorrências referente ao termo de evocação água. elemento em comum no núcleo central de duas representações sociais. A inclusão ocorre quando um dos núcleos centrais repete todos os elementos do outro. Por fim, a relação de reciprocidade se dá quando um cada um dos objetos figura como elemento central na representação do outro, como acontece nos estudos sobre a representação social do trabalho e do dinheiro, em que o elemento dinheiro fazia parte do núcleo central da representação social do trabalho, e o elemento trabalho era central na representação social do dinheiro (Flament, 2001).

A representação social da água compartilha alguns elementos centrais com a representação social do meio ambiente, de modo que se pode afirmar que as duas representações possuem uma relação de conjunção. Por sua vez, o elemento água é um elemento central na representação social do meio ambiente. No entanto meio ambiente não é elemento central na representação social da água o que descaracteriza a relação de reciprocidade entre as duas representações. A Figura 5 ilustra a conexão entre os elementos.

A presença do elemento água como central na representação social do meio ambiente indica que o elemento natural que mais se destaca como descritivo do meio ambiente é a água. Os elementos saúde e poluição são centrais em ambas as representações e indica que tanto a representação social da água quanto a representação social do meio ambiente estão ligadas a preocupações com

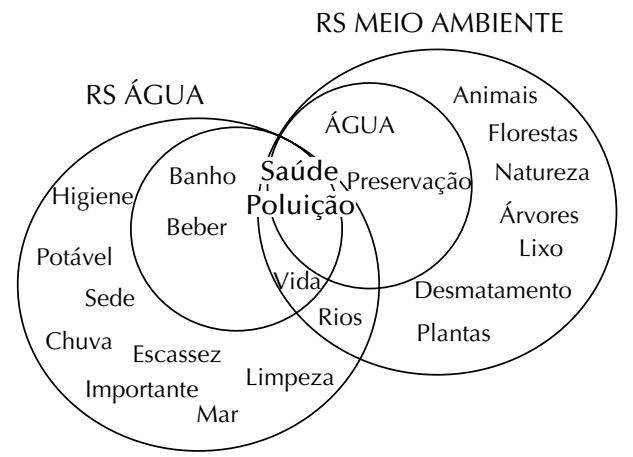

Figura 5. Relação entre elementos da representação social da água e da representação social do meio ambiente. 
seu cuidado, pois poluir a água significa poluir o meio ambiente e vice-versa. O elemento saúde indica que as pessoas consideram que tanto água quanto meio ambiente influenciam na saúde individual.

Outros elementos, tanto do sistema central, quanto do sistema periférico que não coincidem entre as duas representações ilustram a especificidade de cada uma das representações, demonstrando que se tratam de representações distintas que compartilham elementos, mas, apesar disso, mantêm suas peculiaridades, garantindo que cada um dos elementos possui sua própria representação social, já que ambos são objetos socialmente relevantes.

\section{Discussão}

O meio ambiente apresenta três aspectos em sua representação social. Os elementos que o compõem são destacados e o elemento mais importante, que tem papel central na representação, é a água. Além disso, a preocupação com seu cuidado também recebe importância e finalmente seu papel na manutenção da saúde. Entre os elementos periféricos, a descrição do meio ambiente ganha importância, seja através de suas características ou mesmo dos recursos que o compõem.

Na representação social do meio ambiente não foram identificadas diferenças significativas entre as faixas etárias, a não ser pela preocupação com os animais, que está fortemente presente no pensamento dos mais jovens (faixa etária 1 - entre 18 e 29 anos) e que não tem destaque no pensamento dos respondentes da faixa etária 3 (60 anos ou mais). A preocupação com o cuidado com os animais e com a possível extinção de algumas espécies pode justificar a preocupação dos respondentes mais jovens, que desde cedo foram orientados sobre esse assunto, seja na escola ou pelos meios de comunicação de massa.

As representações sobre o meio ambiente não demonstraram ser influenciadas pela faixa etária dos respondentes, de modo que as pessoas se apropriaram do paradigma antropocêntrico ou ecológico, ou mesmo de ambos, de acordo com outras variáveis que não foram identificadas neste estudo. As representações identificadas demonstram o predomínio de cognições compatíveis com o paradigma ecológico, pois um dos três eixos de maior destaque na representação social do meio ambiente identificada se relaciona com as preocupações ambientais. Outro eixo central considera a importância do meio ambiente para a saúde, de modo que as pessoas se reconhecem como parte desse ambiente, cognição que se assemelha ao paradigma ecológico.

A representação social da água identificada indica que o pensamento social sobre esse elemento natural está voltado para três aspectos importantes. Seu uso cotidiano, identificado como um elemento presente no dia a dia e que, portanto, tem sua importância destacada em seu aspecto mais imediato, mais individual. Sua importância para a manutenção da saúde e da vida no planeta, considerando seus aspectos mais amplos, mais globais. O terceiro aspecto é a noção que de é um elemento que vem sendo degradado. O terceiro aspecto parece ter relação com os dois primeiros, pois a poluição das águas prejudica seu uso cotidiano e também coloca em risco a manutenção da saúde e da vida no planeta.

Abric (2003) destaca o caráter destaca o caráter estável do núcleo central de uma representação social, de modo que os elementos que fazem parte desse núcleo resistem às mudanças por um determinado período de tempo, que costuma ser longo, alguns elementos que pertencem à periferia da representação ao longo do tempo podem tornar-se centrais, assim como alguns elementos centrais podem migrar para a periferia se deixarem de ser importantes. Essas alterações no sistema central de uma representação social indicam que a própria representação sofreu modificações ao longo do tempo.

Diferenças entre as representações sociais de pessoas com faixas etárias distintas podem 
fornecer pistas de tais modificações, pois como o processo de transformação ocorre lentamente, diferentes elementos nos núcleos centrais podem indicar um caminho pelo qual a transformação de uma representação social vem transcorrendo. Daí a importância das diferenças encontradas entre os respondentes da faixa etária 1 (entre 18 e 29 anos) e 3 (60 anos ou mais), que indicam o caminho de transformação da representação social da água nas ultimas décadas.

Os respondentes da faixa etária 3 (60 anos ou mais) destacam com maior importância aos aspectos cotidianos do uso da água. Já os respondentes da faixa etária 1 (entre 18 e 29 anos) destacam seu aspecto mais global. Os respondentes da faixa etária 2 , intermediária, compartilham de ambos os pensamentos, o que reforça a ideia de que a mudança na representação ocorre ao longo do tempo. A preocupação com a poluição da água está presente no pensamento de todos os grupos, o que se deve ao ser caráter abrangente e transversal, pois a poluição prejudica a água em todos os seus aspectos e usos, além de estar muito presente no discurso da mídia e na vida cotidiana dos moradores da grande Florianópolis, que convivem de perto com a poluição das Baías Norte e Sul.

Mesmo se tratando de um estudo exploratório, existem indicativos de que a representação social da água vem passando por transformações. Anteriormente ela era vista como um elemento para uso cotidiano, pessoal; um bem individual. Atualmente vem ganhando espaço o pensamento de que a água é um bem comum, que deve servir a todos e ter qualidade, pois ela tem grande influência sobre a saúde e é, acima de tudo, o elemento que possibilita a continuidade da vida no e do planeta Terra.
A relação existente entre as duas representações sociais também merece destaque, pois, conforme Flament e Rouquette (2003) duas representações sociais que possuem elementos comuns em seus núcleos centrais estão em uma relação de conjunção e indicam uma ligação entre as duas representações sociais. A própria presença do elemento água como central na representação social do meio ambiente indica essa ligação. Pode-se dizer que água e meio ambiente estão relacionados no pensamento popular, ainda que a água não remeta diretamente ao meio ambiente, ela possui em comum com o meio ambiente um importante papel na manutenção da saúde e a preocupação com a poluição que ambos vêm sofrendo.

Por outro lado, pensar em meio ambiente faz pensar em água, pois a água é o elemento natural que recebeu maior destaque na representação social do meio ambiente. O próprio pensamento popular destaca a importância que a água possui, seja como um bem individual no uso cotidiano, seja como um bem comum que possibilita a existência ou manutenção da vida na Terra. Cada vez mais o pensamento social se volta para a preocupação e o cuidado com esse elemento, o que pode ser resultado do trabalho de educação ambiental, cada vez mais presente nas escolas, ou ainda da mídia, que têm dado amplo espaço ao tema. É importante destacar que os dados encontrados nesse estudo reforçam a efetividade do discurso do cuidado ambiental, que cada vez mais ganha espaço no pensamento social e abre caminhos para comportamentos efetivamente voltados ao cuidado com a água e com o meio ambiente de modo geral. 
Abric, J. C. (1998). A abordagem estrutural das representações sociais. In A. S. P. Moreira, \& D. C. Oliveira (Eds.), Estudos interdisciplinares de representação social (pp. 27-38). Goiânia, GO: A B.

Abric, J. C. (2003). Abordagem estrutural das representações sociais: desenvolvimentos recentes. In P. H. F. Campos, \& M. C. S. Loureiro (Eds.), Representações sociais e práticas educativas (pp. 37-57). Goiânia, GO: Ed. da UCG.

Corral-Verdugo, V. (2005). Psicologia ambiental: objeto, "realidades" sócio-físicas e visões culturais de interações ambiente-comportamento. Psicologia USP, 16(1-2), 71-87. do:10.1590/S0103-65642005000100009

Félonneau, M. L. (2003). Les représentations sociales dans le champ de l'environnement. In G. Moser, \& K. Weiss (Eds.), Espaces de vie: aspects de la relation homme-environnement (pp. 145-176). Paris: Armand Colin.

Flament, C. (2001). Estrutura e dinâmica das representações sociais. In D. Jodelet (Ed.), As representações sociais (pp. 173-186). Rio de Janeiro: EdUERJ.

Flament, C., \& Rouquette, M. L. (2003). Anatomie des idées ordinaires. Paris: Armand Colin.

Jodelet, D. (2001). Representações sociais: um domínio em expansão. In D. Jodelet (Ed.), As representações sociais (pp. 17-44). Rio de Janeiro: EdUERJ.

Kuhnen, A. (2002). Lagoa da Conceição: meio ambiente e modos de vida em transformação. Florianópolis, SP: Cidade Futura.

Moraes, D. S. L., \& Jordão, B. Q. (2002). Degradação de recursos hídricos e seus efeitos sobre a saúde humana. Revista de Saúde Pública, 36(3), 370-374. doi:10.1590/S0034-89102002000300018

Moreira, M. M. M. A. (2006). A política nacional de recursos hídricos: avanços recentes e novos desafios.. In N. Felicidade, R. C. Martins, \& A. A. Leme (Eds.), Uso e gestão dos recursos hídricos no Brasil: velhos e novos desafios para a cidadania (pp. 70-76). São Carlos, SP: Rima.

Moscovici, S. (1978). A representação social da psicanálise. Rio de Janeiro: Zahar.
Moscovici, S. (1982). On social representation. In J. P. Forgas (Ed.), Social cognition (pp. 181-209). Londres: Academic Press.

Nascimento-Schulze, C. M., Fragnani, E. F. S., Carboni, L. R., \& Maliska, M. E. (2002). Atitudes frente ao novo paradigma ambiental: um estudo no contexto turístico de Florianópolis. Revista de Ciências Humanas, Especial temática, 215-224.

Pinheiro, J. Q. (2002). Comprometimento ambiental: perspectiva temporal e sustentabilidade. In J. G. Martínez \& S. M. Doménech (Eds.), Temas selectos de psicologia ambiental (pp. 463-481). México: Unam-Greco-Fundación Unilibre.

Polli, G. M., Kuhnen, A., Azevedo, E. G., Fantin, J., \& Silva, R. F. G. (2009). Representações sociais da água em Santa Catarina. Psicologia em Estudo, 14(3), 529-536. doi:10.1590/S1413-73722009000300014

Rouquette, M. L. (1998). Representações e Práticas Sociais: alguns elementos teóricos. In A. S. P. Moreira, \& D. C. Oliveira (Eds.), Estudos interdisciplinares de representação social (pp. 39-46). Goiânia: AB.

Souza Junior, W. C. (2004). Gestão das águas no Brasil: reflexões, diagnósticos e desafios. São Paulo, SP: Pierópolis.

Torres, T. L. (2010). Pensamento social sobre envelhecimento, idoso e rejuvenescimento para diferentes grupos etários. Tese de Doutorado. Universidade Federal de Santa Catarina, Florianópolis, SC.

Vèrges, P. (1997). SIMI - analyse de similitude de questionnaires et de données numériques: manuel version 1.2. Aix-en-Provence: LAMES.

Vèrges, P. (1999). Esemble de programmes permettant l'analyse des evocations: manuel version 2. Aix-en-Provence: LAMES.

Wachelke, J. F. R., \& Camargo, B. V. (2007). Representações sociais, representações individuais e comportamento. Revista Interamericana de Psicologia, 41(3), 379-390.

Wiesenfeld, E. (2005). A psicologia ambiental e as diversas realidade humanas. Psicologia USP, 16(1), 53-69. doi:10.1590/S0103-65642005000100008 


\section{Gislei Mocelin Polli}

Doutora pela Universidade Federal de Santa Catarina - SC. Brasil.

Email: gismocelin@gmail.com

\section{Brigido Vizeu Camargo}

Doutor pela Universidade Federal de Santa Catarina - SC. Brasil.

\section{Endereço para envio de correspondência:}

Gislei Mocelin Polli. Rua Francisco Guilherme Bahr, 289. Ap. 12. Tingui. CEP: 82620070. Curitiba - PR. Brasil.

Recebido: 22/07/2013, Aprovado: 24/06/2015. 